\title{
The Impact of Opinion Leadership on Purchases through Social Networking Websites
}

\section{Viju Raghupathi' and Joshua Fogel ${ }^{2}$}

${ }^{1}$ Brooklyn College, City University of New York, Brooklyn, New York, USA, Vraghupathi@brooklyn.cuny.edu

${ }^{2}$ Brooklyn College, City University of New York, Brooklyn, New York, USA, jfogel@brooklyn.cuny.edu

Received 21 February 2014; received in revised form 12 October 2014; accepted 13 October 2014

\begin{abstract}
Social media is used as a platform to not only make connections and share user-generated content but also to advertise products. We study the role of opinion leadership on the social media networking website of Facebook for product advertisements through news feeds and wall postings. We found that perceived benevolence of the opinion leader posting advertisements was significantly associated with increased intentions to purchase and also increased purchase behavior. Also, although the Theory of Planned Behavior variables of increased attitudes, social norms, and behavioral control were significantly associated with increasing purchase intentions, only purchase intentions was significantly associated with purchase behavior. Type of friend was significantly associated with purchase intention but no relationship occurred for purchase behavior. Management information systems professionals involved with the development of social networking websites should consider perceived benevolence as an area of importance for interesting consumers to explore and use newly developed aspects of social networking websites. Marketers should ensure that their advertisements on social networking websites are perceived by consumers as benevolent.
\end{abstract}

Keywords: Social network, Facebook, Opinion leadership, Opinion seeking, Planned behavior 


\section{Introduction}

Social media are online platforms that allow people to form a community to create and share content to communicate and to build relationships [27], [33], [50], [54]. Text picture audio and/or video can be used depending upon the type of social media platform [69]. There are several kinds of social media such as social networks, blogs, wikis, podcasts, forums, virtual game worlds, and content communities [40]. Facebook is the most commonly used social network with $67 \%$ of online users using it in the United States [19].

Social media is predominantly used for communication [20]. College students use social networks for socializing and for legitimacy in presenting themselves as an entity with personal and professional attributes [68]. Also, social media helps college students shape their social and professional identities through self-presentation of both social and professional information in their profiles [30].

Social media is used not only as a platform to make connections and share user-generated content but also to evaluate products, make recommendations on purchases, and link current purchases to future purchases through status updates and twitter feeds [23]. Consumers search for information on social media before making a purchase decision. Companies view consumers' social media activities to better understand their product brand image and to identify potential customers [31]. Also, companies use social media to influence consumer behavior for purchase decisions through electronic word of mouth [12], [32], [34], [65], [71] or word of mouse marketing (i.e., mouse representing the computer mouse) [14], [38]. Social media offers a wide reach since it is accessible by the general public. Therefore, companies are looking for ways to harness the robustness of social media in creating awareness and in enhancing their customer relations.

Internet users spend about 7 hours more per month on average on the social media website of Facebook than they spend on search engines and websites of Google, Yahoo, YouTube, Microsoft, Wikipedia and Amazon combined [58]. Therefore, using Facebook to market a brand offers good potential to businesses. Facebook and other social networks now offer features and functionality that are similar to the feedback and reputation mechanisms of sites such as eBay and Amazon. This versatility allows social networks to become full fledged recommendation systems [29]. Facebook allows many social plug-ins including a like feature where people can like a particular posting or photo; the wall feature which is similar to a bulletin or chalk board where users post updates on their wall or on their friends' walls; and the newsfeed feature which is a list of stories or content from people that users follow. In our research, we study the role of opinion leadership and opinion seeking on Facebook for product advertisements through the features of news feeds and wall postings.

\section{Literature Review}

This section reviews the literature on opinions, Theory of Planned Behavior, demographics and friends.

\subsection{Opinions}

In an information economy where information is a prime component, information dissemination in the form of opinions on products and services play an integral role in influencing decision making. Informal communication that occurs over the Internet/social media about the ownership, usage, or characteristics of a product or service, is referred to as electronic word of mouth. The two parties in the information dissemination process include the source or the opinion leader, and the recipient or the opinion seeker.

Opinion leaders exert an influence on the opinions of others [65]. They earn the trust of users [56], [59] and lead them to perform a purchase and/or click online [38]. The credibility of a message can depend on the credibility of the opinion leader [12]. Research on opinion leadership looks at the types of opinion leaders in terms of those with a single area of expertise or multiple areas of expertise [18], [26], the characteristics of opinion leaders [11], [67], [77], whether opinion leaders are experts in the field of advice [65], and the role of opinion leaders in diffusion of innovation [26], [67], [73]. There is research on opinion leadership in a general online context. For example, opinion leaders due to their word of mouth influence increase the rate of diffusion of products and services [12]; earn the trust of web users and help them perform a purchase-click online to purchase products and services [38]; are influential in determining shopping trends [35] and in innovation adoption [5]; and signal product quality and attributes to influence potential adopters online [47], [70]. However, there is limited research on opinion leadership and social networking [29]. With social media becoming prolific on the Internet, it is important to analyze the extent to which opinion leadership contributes to consumer purchases on Internet social media through social networking websites.

As opinion leaders must be trusted in order to exert influence [56], studies on opinion leadership investigate the dimensions of trust [52] such as benevolence [10], [49] and integrity [15], [21], [74]. Benevolence is a dimension of trust [22], [49], [53] that shows a willingness on the part of the trustor to take into consideration the opinion leader's interests in a decision making process [4] by expressing care and concern for the opinion leader. Integrity is the perception that the opinion leader has principles that are acceptable to the trustor [74]. Also trustors are more likely 
to follow the recommendations and opinions of opinion leaders who display values that are similar to those of the trustors [66].

Opinion leadership is based on the premise that opinion seekers seek advice and follow the opinions and recommendations of opinion leaders [22]. The two-step flow model of communication emphasizes that opinion leaders learn from and form opinions from the mass media and then pass on this content to others named opinion seekers [41]. Opinion seeking is one aspect of what consumers look for when seeking information to decide whether to purchase a product [22]. It is part of the external information search. Opinion seeking is a way in which consumers reduce the risk in their purchase decision.

Consumers who seek product recommendations from online sources select the recommended product twice as often as others who do not seek any recommendations [75]. Studying the information seeking behavior (opinion seeking) is as important as studying the information sharing behavior (opinion leadership) of people, since opinion seeking lays the foundation for the occurrence of opinion leadership.

We propose an overarching research question with regard to opinions as:

RQ1: What is the role of opinions in leading to intention to purchase and behavior of purchase through news feeds and wall postings on the Facebook social networking website?

Breaking down the above research question in terms of the components of opinion leadership and opinion seeking, we propose:

RQ1a: Is opinion leadership associated with the intention to purchase a product advertised through a news feed or wall posting on the Facebook social networking website?

RQ1b: Is opinion leadership associated with purchase behavior of a product advertised through a news feed or wall posting on the Facebook social networking website?

RQ2a: Is opinion seeking associated with the intention to purchase a product advertised through a news feed or wall posting on the Facebook social networking website?

RQ2b: Is opinion seeking associated with purchase behavior of a product advertised through a news feed or wall posting on the Facebook social networking website?

\subsection{Theory of Planned Behavior}

While the central concepts in our research relate to the role of opinion leadership and opinion seeking on the intention and purchase behavior of products, we use the Theory of Planned Behavior as the theoretical framework for our study.

The Theory of Planned Behavior [2] explains that behavioral intention (e.g., purchase intention) is determined by three antecedents of the attitude that the person holds towards the behavior (e.g., purchase attitude), social norms for the behavior (e.g., perceived opinion of others about purchasing), and the degree of control that the person feels over performing the behavior (e.g., perceived purchasing behavioral control) [13], [63]. The Theory of Planned Behavior framework has been used in many studies for purchasing behavior. It has been used to study attitudes towards online shopping behavior and purchase intention [51]; social orientation and personal values and attitudes of students towards online shopping [3]; and consumer willingness to buy groceries online [28]. We find it appropriate to use this theoretical framework to explain our intention to and the behavior of purchase of a product advertised through a news feed or wall posting on Facebook. We look at the attitudes of the Facebook user towards the advertisement, which may impact the intention or behavior of purchase; the social norms that the Facebook user holds, which may impact the intention or behavior of purchase; and the extent of behavioral control that the Facebook user exercises, which may impact the intention or behavior of purchase of the advertised product on Facebook. Even though our research focuses on the concepts of opinion leadership and opinion seeking, we look at these variables to support our theoretical framework.

We look at the following proposition relating to our theoretical framework:

Are attitudes, social norms, and perceived behavioral control associated with the intention to and the behavior of purchase of a product advertised through a news feed or wall posting on the Facebook social networking website? 


\subsection{Demographics}

We use the demographic variables as control variables in our research. Demographics on the users of social media can provide an understanding of trends and patterns of usage. Young adults and adults from the ages of 18 to 39 years are those ages most likely to use social networks [19]. With regard to sex, one study reports that $71 \%$ of women who use the Internet use social networking websites as compared to 62\% of men [19]. However, another study [62] did not find any significant differences between men and women for frequency of social networking website use. With regard to race/ethnicity, $65 \%$ of Internet users who are white use a social networking website, while $68 \%$ of black Internet users use a social networking website [19].There are different ways in which different racial/ethnic groups respond to advertisements on social networking websites. Among whites, $13 \%$ shared advertisements and 12\% purchased products. Among Hispanics, $21 \%$ shared advertisements and $22 \%$ purchased products. Among Asians, 26\% shared advertisements and 31\% purchased products [58].

The culture of a person can influence the way one perceives online reviews of products. People from countries such as Korea [61] and China [36] have collectivist cultural characteristics and use indirect or circular communication patterns. These Asian users rely on word of mouth or online recommendations and perceive such recommendations to be more useful [55], [61] than users from countries such as the United States that have individualist cultural characteristics and use direct communication patterns [55], [61]. This perceived usefulness of online reviews has an influence on purchase decisions [61]. Users from collectivist cultures can potentially be more influenced by online recommendations on social media for online purchase decisions than users from individualist cultures.

As demographics are potentially important for purchase decision, we look at the following proposition:

Are the variables of age, sex, race/ethnicity, and being born in the United States associated with the intention to and behavior of purchase of a product advertised through a news feed or wall posting on the Facebook social networking website?

\subsection{Friends}

In addition to demographics, we use friends as a control variable in our research. Among college students, relationships with friends are closer than with siblings [64]. Social media and social networks in particular can facilitate making friends and maintaining friendships. The most popular social networking website of Facebook has users create profiles and collect friends. Traditionally, friends are defined as those who engage in mutual companionship, support and intimacy [72] and offer emotional and practical support [6]. In Facebook, a user can create a profile and collect friends [80] by sending requests. If the receiver accepts the friend request, he/she can be listed as a friend. The profile lists the number of friends for the Facebook user. The wall feature on Facebook is a space on a user's profile in which the user or friends can post comments, pictures, videos, or music clips. Facebook also offers the news feed feature which offers the user and friends information about each other's activities. There are different kinds of friendships for Facebook users. Close friends are people that users interact with using different channels of communication such as face-to-face, e-mail and Facebook while acquaintances are people that users interact with primarily using Facebook [9]. Many of the friends on Facebook may be acquaintances and not close friends.

Facebook offers many social plug-in tools to marketers which provide the opportunity for marketers to increase their engagement with customers [29]. These include the like button, news feeds, and wall postings. Consumers report that a positive referral from a Facebook friend makes them more likely to visit or purchase from a retailer [60]. About $33 \%$ of Facebook users are reported to be fans of brands, and from these fans, $60 \%$ are more likely to purchase or recommend to a friend after liking a brand [60]. Users of Facebook also report that they like to show brand support to their friends [29] by endorsing the opinions or recommendations of brands that they suggest. Also, each time a Facebook user interacts with a brand, this activity is displayed in the news feeds of their Facebook friends.

Due to the important role that friends play in Facebook, we look at the following proposition relating to Facebook friends:

Are Facebook friends associated with the intention to and behavior of purchase of a product advertised through a news feed or wall posting on the Facebook social networking website?

\section{Methods}

This section describes the methods used. We describe the participants and procedures, measures used, and statistical analyses used to analyze the data. 


\subsection{Participants and Procedures}

We surveyed 700 college students from an undergraduate college in New York City. The survey response rate was $97.9 \%$ which was calculated from the 700 completed surveys received from the 715 individuals approached to complete the survey [700/715*100]. As we wanted a consistent sample in the age group below 36, the data analyzed consisted of 675 participants. Participants were asked to complete an anonymous survey in classrooms. All participants provided informed consent. The survey was declared exempt from formal ethical review by the college Institutional Review Board. Data were collected in August 2012.

\subsection{Measures}

This section reviews the literature on opinions, demographics, Theory of Planned Behavior, friendship and outcome variables.

\subsubsection{Opinions - Opinion Leadership and Opinion Seeking Variables}

Benevolence was measured with three items using a Likert-type scale that ranged from 1=strongly disagree to $7=$ strongly agree. The scale was adapted from [45], [53] where we modified items to represent our context by including the phrase of person who sent the Facebook advertisement through a news feed or wall posting in place of the original phrase of the company name of LegalAdvice. A sample item is, I believe the person who sent the Facebook advertisement through a news feed or wall posting would act in my best interest. Greater levels of benevolence are indicated by higher scores. In this sample, Cronbach alpha was 0.80 .

Integrity was measured with four items using a Likert-type scale that ranged from 1=strongly disagree to $7=$ strongly agree. The scale was adapted from [53] where we modified items to represent our context by including the phrase of person who sent the Facebook advertisement through a news feed or wall posting in place of the original phrase of the company name of LegalAdvice. A sample item is, I expect to seek additional information about a product after seeing a Facebook advertisement through a news feed or wall posting for the product. Greater levels of integrity are indicated by higher scores. In this sample, Cronbach alpha was 0.79 .

Opinion seeking was measured with eight items using a Likert-type scale that ranged from $1=$ strongly disagree to $7=$ strongly agree. The scale was adapted from [22] where we modified items to represent our context by including the phrase of purchasing a product in place of the original phrase of buying a cd or tape. A sample item is, When I consider purchasing a product I ask people for advice. There are three items that are reverse coded. Greater levels of opinion seeking are indicated by higher scores. In this sample, Cronbach alpha was 0.80 .

\subsubsection{Demographic Variables}

The personal demographic variables were age measured in years, sex measured as man and woman, and race/ethnicity measured in categories of White, African-American, Hispanic-American, Asian-American, South-Asian, and other. In addition, we asked whether the participant was born in the United States, measured as yes or no. Table 1 in our Results section shows our demographic variables.

\subsubsection{Theory of Planned Behavior Variables}

Intentions were measured with three items using a Likert-type scale that ranged from $1=$ strongly disagree to $7=$ strongly agree. The scale used the framework for creating Theory of Planned Behavior items from [24]. A sample item is, I expect to seek additional information about a product after seeing a Facebook advertisement through a news feed or wall posting for the product. Greater levels of intentions are indicated by higher scores. In this sample, Cronbach alpha was 0.93 .

Attitudes were measured with four items using a Likert-type scale that had negative and positive topics as endpoints (e.g., 1 =worthless to 7 =useful). The scale used the framework for creating Theory of Planned Behavior items from [24]. A sample item is Obtaining more information about a product advertised through a news feed or wall posting on Facebook is (worthless....... useful). There are two items that are reverse coded. Greater levels of attitudes are indicated by higher scores. In this sample, Cronbach alpha was 0.74 .

Social norms were measured with three items using a Likert-type scale that ranged from $1=$ strongly disagree to $7=$ strongly agree. The scale used the framework for creating Theory of Planned Behavior items from [24]. A sample item is, It is expected of me that I seek additional information about a product after seeing a Facebook advertisement through a news feed or wall posting for the product. Greater levels of social norms are indicated by higher scores. In this sample, Cronbach alpha was 0.72 .

Behavior control was measured with four items using a Likert-type scale that ranged from 1=strongly disagree to $7=$ strongly agree. These items used the framework for creating Theory of Planned Behavior items from [24]. A sample item is, I am confident that if I wanted to I could seek additional information about a product after seeing a 
Facebook advertisement through a news feed or wall posting for the product There are two items that are reverse coded. Due to poor Cronbach alpha reliability for the total score, each item was analyzed individually.

\subsubsection{Friendship Variable}

Prior research studies friendship in terms of advice networks in an organization [25] and in terms of specific workrelated advice [43]. It is important to consider friendship in social media networks for a few reasons. First, social media networking is the emerging communication technology in the digital era. Second, in social networking websites such as Facebook, the interaction rules for friends may be different from that in offline settings [9]. Third, the kind of interaction in a social networking website like Facebook may differ based on the type of friend [8] who is communicating. For example, there may be friends that a user interacts with actively offline and online on Facebook, or passively on Facebook by monitoring this friend's updates. We asked, In general, when viewing Facebook advertisements through a news feed or wall posting, which type of friend's posting do you value the most for influencing your decision to purchase a product? Participants chose one choice of a face-to-face friend who is also a Facebook friend, a Facebook friend, or no difference.

\subsubsection{Outcome Variables}

The outcome variables were intention to purchase which was measured as, In the past 3 months, did a Facebook advertisement through a news feed or wall posting influence your decision to purchase the product? Purchase behavior was measured using the aggregate of purchase behavior for all six product categories of designer clothing, cosmetic or beauty product, health product, weight loss product, computer product [hardware or software], and gambling product.

\subsection{Statistical Analyses}

Descriptive statistics were calculated for all the variables with mean and standard deviation for the continuous variables, and percentage and frequency for the categorical variables. Inferential statistics of linear regression was used for the outcome variables of intentions and purchase behavior. As purchase behavior had a skewed distribution with values of zero, the value of one was added to all participants and then logarithmic transformed. Analyses were performed using IBM SPSS Statistics Version 19 [IBM 2010]. All p-values were two-sided.

Table 1: Descriptive statistics for the sample

\begin{tabular}{|c|c|c|}
\hline Variables & Mean (SD) & Percentage (\#) \\
\hline Age (years) & $22.4(3.45)$ & \\
\hline Sex (women) & & $50.7 \%$ (342) \\
\hline $\begin{aligned} \text { Race/Ethnicity } \\
\text { - White } \\
\text { - African-American } \\
\text { - Hispanic-American } \\
\text { - Asian-American } \\
\text { - } \text { South-Asian } \\
\text { Other }\end{aligned}$ & & $\begin{array}{l}34.4 \%(232) \\
15.7 \%(106) \\
9.3 \%(63) \\
27.0 \%(182) \\
5.3 \%(36) \\
8.3 \%(56)\end{array}$ \\
\hline Born in the United States & & $56.6 \%(382)$ \\
\hline Opinion Leadership - Benevolence & $9.1(3.92)$ & \\
\hline Opinion Leadership - Integrity & $9.2(3.78)$ & \\
\hline Opinion Seeking & $35.0(8.65)$ & \\
\hline Attitudes & $16.97(4.59)$ & \\
\hline Social Norms & $8.7(4.04)$ & \\
\hline Confident that I could seek additional information about a product & $4.6(1.76)$ & \\
\hline $\begin{array}{l}\text { For me to seek additional information about a product is difficult } \\
\text { (reverse) }\end{array}$ & $5.2(1.47)$ & \\
\hline $\begin{array}{l}\text { Decision to seek additional information about a product is beyond } \\
\text { my control (reverse) }\end{array}$ & $5.4(1.59)$ & \\
\hline $\begin{array}{l}\text { Whether I seek additional information about a product is entirely } \\
\text { up to me }\end{array}$ & $5.4(1.78)$ & \\
\hline $\begin{array}{ll}\text { Friend } & \\
\text { - Face-to-face friend who is also a Facebook friend } \\
\text { - Facebook friend } \\
\text { - No difference }\end{array}$ & & $\begin{array}{l}75.0 \%(506) \\
4.4 \%(30) \\
20.6 \%(139)\end{array}$ \\
\hline Intentions & $10.5(5.11)$ & \\
\hline Product categories purchases (number) & $0.73(1.24)$ & \\
\hline
\end{tabular}




\section{Results}

Table 1 shows the descriptive statistics of the sample. Mean age was slightly above 22 . There was almost equal representation for the sexes. Race/ethnicity was very diverse with more than one-third white, more than one-quarter Asian-American, and the rest from a number of racial/ethnic groups. Slightly more than half were born in the United States. The mean score for the items relating to both benevolence and integrity were in the direction of strongly disagree. The mean score for items relating to opinion seeking was slightly in the direction of strongly agree. The mean score for the items relating to attitudes was neutral between positive and negative. The mean score for items relating to social norms was in the direction of strongly disagree. The score for each of the four items of behavior control was either neutral or slightly in the direction of strongly agree. Three-fourths stated that they valued the postings from a face-to-face friend who is also a Facebook friend, while one-fifth said that it made no difference to them whether it was a Facebook friend or a face-to-face friend who was also a Facebook friend. The mean score for items relating to intentions was slightly in the direction of strongly disagree. Mean number of products purchased was less than one product.

Table 2 shows the linear regression analysis for intention to purchase a product advertised on Facebook through news feeds or wall postings by one's Facebook friends. The only statistically significant demographic variable was age with an increased association with increased intentions. With regard to the opinion leadership variables, both increased benevolence and integrity had statistically significant increased associations with increased intentions. With regard to the Theory of Planned Behavior variables, both increased attitudes and social norms had statistically significant increased associations with increased intentions. With regard to behavior control, the item of seeking additional information about a product after seeing a Facebook advertisement through a news feed or wall posting is entirely up to me had a statistically significant association with increased intentions. With regard to the friend variable, those for whom there was no difference in the person posting the wall posting or news feed being a Facebook friend or a face-to-face friend who was also a Facebook friend, had significantly decreased association with intentions to purchase.

Table 2: Linear regression analysis for intention

\begin{tabular}{|c|c|c|c|}
\hline Variables & Beta & SE & p-value \\
\hline Age (years) & 0.13 & 0.05 & 0.01 \\
\hline Sex (women) & 0.25 & 0.31 & 0.42 \\
\hline $\begin{aligned} \text { Race/Ethnicity } \\
\text { - } \\
\text { - } \text { African-American } \\
\text { - Hispanic-American } \\
\text { - Asian-American } \\
\text { - South-Asian } \\
\text { - Other }\end{aligned}$ & $\begin{array}{l}\text { Reference } \\
0.05 \\
0.76 \\
-0.28 \\
0.45 \\
-0.31\end{array}$ & $\begin{array}{l}0.47 \\
0.56 \\
0.41 \\
0.72 \\
0.59\end{array}$ & $\begin{array}{l}0.92 \\
0.18 \\
0.49 \\
0.53 \\
0.60\end{array}$ \\
\hline Born in the United States & -0.18 & & 0.60 \\
\hline Benevolence & 0.23 & 0.06 & $<0.001$ \\
\hline Integrity & 0.21 & 0.06 & $<0.001$ \\
\hline Opinion Seeking & 0.03 & 0.02 & 0.10 \\
\hline Attitudes & 0.27 & 0.04 & $<0.001$ \\
\hline Social Norms & 0.37 & 0.05 & $<0.001$ \\
\hline $\begin{array}{l}\text { Confident that I could seek additional information } \\
\text { about a product }\end{array}$ & 0.01 & 0.10 & 0.92 \\
\hline $\begin{array}{l}\text { For me to seek additional information about a product } \\
\text { is difficult (reverse) }\end{array}$ & 0.08 & 0.12 & 0.51 \\
\hline $\begin{array}{l}\text { Decision to seek additional information about a } \\
\text { product is beyond my control (reverse) }\end{array}$ & -0.13 & 0.11 & 0.27 \\
\hline $\begin{array}{l}\text { Whether I seek additional information about a product } \\
\text { is entirely up to me }\end{array}$ & 0.23 & 0.09 & 0.01 \\
\hline $\begin{array}{l}\text { Friend } \\
\text { - Face-to-face friend who is also a Facebook } \\
\text { friend } \\
\text { - Facebook friend } \\
\text { - No difference }\end{array}$ & $\begin{array}{l}\text { Reference } \\
0.45 \\
-0.79\end{array}$ & $\begin{array}{l}0.74 \\
0.38\end{array}$ & $\begin{array}{l}0.54 \\
0.04\end{array}$ \\
\hline Intercept & -5.97 & 1.66 & $<0.001$ \\
\hline
\end{tabular}

Table 3 shows the linear regression analysis for purchase behavior of a product advertised on Facebook through news feeds or wall postings by one's Facebook friends. The only statistically significant demographic variable was Asian American race/ethnicity with a statistically significant increased association with increased purchase behavior. 
With regard to the opinion leadership variables, increased benevolence had a statistically significant increased association with increased purchase behavior. With regard to the Theory of Planned Behavior variables, only the item of behavior control of seeking additional information about a product after seeing a Facebook advertisement through a news feed or wall posting is entirely up to me had a statistically significant decreased association with increased purchase behavior. The friend variable did not have any statistically significant association with purchase behavior. Increased intentions had a statistically significant association with increased purchase behavior.

Table 3: Linear regression analysis for behavior

\begin{tabular}{|c|c|c|c|}
\hline Variables & Beta & SE & p-value \\
\hline Age (years) & -0.004 & 0.003 & 0.10 \\
\hline Sex (women) & 0.02 & 0.02 & 0.25 \\
\hline $\begin{aligned} \text { Race/Ethnicity } \\
\text { - White } \\
\text { - African-American } \\
\text { - Hispanic-American } \\
\text { - Asian-American } \\
\text { - South-Asian } \\
\text { - Other }\end{aligned}$ & $\begin{array}{l}\text { Reference } \\
0.02 \\
0.04 \\
0.06 \\
-0.004 \\
0.05\end{array}$ & $\begin{array}{l}0.03 \\
0.03 \\
0.02 \\
0.04 \\
0.03\end{array}$ & $\begin{array}{l}0.47 \\
0.24 \\
0.01 \\
0.92 \\
0.11\end{array}$ \\
\hline Born in the United States & 0.02 & 0.02 & 0.23 \\
\hline Benevolence & 0.01 & 0.003 & 0.001 \\
\hline Integrity & $<0.001$ & 0.003 & 0.67 \\
\hline Opinion Seeking & $<0.001$ & 0.001 & 0.74 \\
\hline Attitudes & 0.003 & 0.002 & 0.11 \\
\hline Social Norms & 0.005 & 0.003 & 0.09 \\
\hline $\begin{array}{l}\text { Confident that I could seek additional information about } \\
\text { a product }\end{array}$ & -0.001 & 0.01 & 0.84 \\
\hline $\begin{array}{l}\text { For me to seek additional information about a product } \\
\text { is difficult (reverse) }\end{array}$ & 0.002 & 0.01 & 0.79 \\
\hline $\begin{array}{l}\text { Decision to seek additional information about a product } \\
\text { is beyond my control (reverse) }\end{array}$ & -0.003 & 0.01 & 0.61 \\
\hline $\begin{array}{l}\text { Whether I seek additional information about a product } \\
\text { is entirely up to me }\end{array}$ & -0.02 & 0.01 & 0.002 \\
\hline $\begin{array}{ll}\text { Friend } & \\
\text { - Face-to-face friend who is also a Facebook } \\
\text { friend } \\
\text { - Facebook friend } \\
\text { - No difference }\end{array}$ & $\begin{array}{l}\text { Reference } \\
0.02 \\
-0.03\end{array}$ & $\begin{array}{l}0.04 \\
0.02\end{array}$ & $\begin{array}{l}0.61 \\
0.20\end{array}$ \\
\hline Intentions & 0.005 & 0.002 & 0.03 \\
\hline Intercept & 0.07 & 0.09 & 0.48 \\
\hline
\end{tabular}

Note: Beta $=$ unstandardized coefficient, $\mathrm{SE}=$ standard error

\section{Discussion}

In our study of intentions to purchase and purchase behavior of products advertised on Facebook through news feeds or wall postings, we found that the opinion leadership variable of benevolence was significantly associated with both increased intentions and purchase behavior, while integrity was only significantly associated with increased intentions. Opinion seeking was not associated with either intentions or purchase behavior.

We found that the perception that the person posting the advertisements seen on Facebook were in one's best interests (i.e., benevolence) and honest and truthful (i.e., integrity) were significantly associated with increasing intention to purchase the advertised product. Also, we found that benevolence of the person posting the Facebook advertisement was significantly associated with increased purchase behavior. These findings are consistent with previous literature [49], [53], [65], which report that benevolence can increase the potential for a person to exert influence on others' decisions. In our social media context, this was associated with purchase of the advertised product. However, although we found that integrity is associated with increasing intentions, we did not find any significant relationship with purchase behavior. A possible explanation is that judgments of integrity are formed fairly early in a relationship as compared to judgments of benevolence that take time to form [74]. As judgments of benevolence take more time to form, it may concomitantly have a more long-standing impact on the consumer decision of actual purchase behavior. Our findings have direct implications for practice. Marketers looking to use opinion leaders to promote their products on social media need to identify those who may be perceived to be benevolent, as this may lead to successful word of mouth influence. Also, a person who is perceived to be benevolent stands a better chance to influence others on Facebook than one perceived to have integrity. While integrity of the source placing the advertisement has an influence on the intention to purchase a product, it does not 
transform the intention into actual purchase behavior. This is relevant to companies since they are increasingly using social media as a tool to reach out to customers and to transform their relationship with customers.

We found that increased age was associated with increased intentions. Prior research reports increased age to be negatively associated with adoption of online shopping [17], [39], [57]. However, in our research we found increased age to be positively associated with intentions for online purchase. This could be due to the fact that compared to the previous studies, our sample included a younger age group of 18 to 36 years, and so the increasing age really refers to the higher end of the sample which is the age group of $30 \mathrm{~s}$.

We found that Asian-American race/ethnicity was significantly associated with increased purchase behavior as compared to whites. Although we are not aware of a study comparing Asian-American to whites for purchase behavior through social media, in a study of purchase of private label products, whites redeemed more coupons than other racial/ethnic minority groups of African-Americans and Hispanic-Americans [16]. In our study, we show that the Asian-American race/ethnicity was the only one that was significantly associated with purchase behavior of a product. We did not find that sex was significantly associated with intention to purchase and purchase behavior. This is not consistent with prior research findings. Research on online purchases suggests that while women spend more time online than men, men conduct a greater number of online transactions [7], [42], [44], [46], [48], [51]. However, most prior research is in the context of general e-commerce, while our research is in the context of a specialized area of ecommerce of advertisements through news feed or wall posting advertisements on the social networking website of Facebook. It is possible that social media advertising has different patterns for consumer behavior than general online advertising.

We investigated an aspect of culture using the variable of whether the person was born in the United States or not. We did not find any significant association with either intentions to purchase or purchase behavior. Prior research on culture found no support for the hypothesis that migrants from English speaking countries have a higher likelihood of shopping online as do those who are proficient in English language [57]. Our research with social networking websites is similar to this pattern.

Prior studies show that social norms [28], attitudes [1], [3], [78], and behavior control [37], [78], are significant in influencing intention for online purchasing, consistent with the Theory of Planned Behavior. Our findings in the context of social media for attitudes, social norms, and one of the behavioral control items are consistent with prior research that they are significantly associated with intentions to purchase online. However, with regard to actual behavior of purchasing the product advertised on Facebook, we found lack of significance for attitudes and social norms and for the one statistically significant behavior control item, a negative association with purchase behavior, while only increased intentions were significantly associated with increased purchase behavior. In our research with advertisements on social media, variables recommended by the Theory of Planned Behavior for influencing intentions did not have the typical pattern. Apparently, only intention is the key variable for influencing purchase behavior in the social media context of Facebook.

In our research, we considered the type of friendship between the person posting the Facebook advertisement and the Facebook user. We found that three-fourths of users valued postings from a Facebook friend who was also a face-to-face friend, while a smaller group (about one-fifth) were indifferent about the kind of friend who made the posting. We found that indifference about the type of friend who made the posting was significantly associated with decreased purchase intentions. It is logical to assume that those indifferent about the type of friend would have less connection to advertisements posted. These individuals are not differentiating between a face-to-face friend where one may have a stronger relationship and connection than a Facebook friend which may be a more relaxed type of friendship. However, with regard to purchase behavior, there was no difference for type of friend nor was there any significant relationship to purchase behavior. Apparently, in our multivariate framework considering a number of variables, friendship type is not a factor for purchase behavior from advertisements on the social media networking website of Facebook. Other factors are the drivers for purchase behavior.

\section{Limitations and Future Direction}

This study has some potential limitations. First, the study is based on the sample from a single college and may not generalize to other colleges. Second, the sample consists of students in a particular age group. Although college-age students are a major segment of social media networking website users, there are users from other age groups too. Our findings therefore may not be applicable to all age groups. Future research should study other age groups to better understand online purchase behavior in social networking websites. Third, there are various measures for opinion leadership. We used only benevolence and integrity in our study. A more comprehensive analytical model can explore a range of opinion leadership measures such as competence or expertise [25], [49], [65], [76], number of direct and indirect ties that one has within a network [35], [79], extent of knowledge contribution [49], and measures of centrality. Fourth, future research should study with an experimental randomized trial if the opinion leadership aspect of benevolence is effective in translating content on social media towards online purchases. 


\section{Conclusions}

We found that the perceived benevolence of the person placing the advertisement to be significant in influencing intentions and behavior to purchase the advertised product on Facebook. There are many implications for the business robustness of the social media platform of Facebook. Management information systems professionals involved with the development of social networking websites should consider perceived benevolence as an area of importance for interesting consumers to explore and use newly developed aspects of social networking websites. Marketers should ensure that their advertisements on social networking websites are perceived by consumers as benevolent.

\section{References}

[1] A.G. Abdul-Muhmin, Repeat purchase intentions in online shopping: The role of satisfaction, attitude, and online retailers' performance, Journal of International Consumer Marketing, vol. 23, vol. 1, pp. 5-20, 2010.

[2] I. Ajzen, The theory of planned behavior, organizational behavior and human decision processes, vol. 50, pp. 179-211, 1991.

[3] A.K. Al-Swidi, S. Behjad and A. Shahzad, Antecedents of online purchasing intention among MBA students: The case of university Utara Malaysia using the partial least squares approach, International Journal of Business and Management, vol. 7, no. 15, pp. 35-49, 2012.

[4] K. Atuahene-Gima and H. Li, When does trust matter? Antecedents and contingent effects of supervisee trust on performance in selling new products in China and the United States, Journal of Marketing, vol. 66, no. 3, pp. 61-81, 2002.

[5] V. Bilgram, A. Brem and K. Voigt, User-centric innovations In new product development - systematic identification of lead users harnessing interactive and collaborative online-tools, International Journal of Innovation Management, vol. 12, no. 3, pp. 419-458, 2008.

[6] D. Boyd. (2006, December) Friends, friendsters, and Myspace Top 8: Writing community into being on social network sites. First Monday. [Online]. Available: http://firstmonday.org/ojs/index.php/fm/article/view/1418/1336

[7] M. Brown, N. Pope and K. Voges, Buying or browsing? An exploration of shopping orientations and online purchase intention, European Journal of Marketing, vol. 37, no. 11/12, pp. 1666-1684, 2003.

[8] E.M. Bryant and J. Marmo. (2010) Relational maintenance strategies on Facebook. Trinity University. [Online]. Available: https://new.trinity.edu/faculty/erin-m-bryant-sumner

[9] E.M. Bryant and J. Marmo, The rules of facebook friendship: A two-stage examination of interaction rules in close, casual, and acquaintance friendships, Journal of Social and Personal Relationships, vol. 29, no. 8, pp. 1013-1035, 2012.

[10] R.S. Burt, Structural holes and good ideas, American Journal of Sociology, vol. 110, no. 2, pp. 349-399, 2004.

[11] K..K. Chan and S. Misra, Characteristics of the opinion leader: A new dimension, Journal of Advertising, vol. 19, no. 3, pp. 53-60, 1990

[12] M.Y. Cheung, C. Luo, C.L. Sia, and H. Chen, Credibility of electronic word-of-mouth: Informational and normative determinants of on-line consumer recommendations, International Journal of Electronic Commerce, vol. 13, no. 4, pp. 9-38, 2009.

[13] N. Delafrooz, L.H.J. Paim and A. Khatibi, A research modeling to understand online shopping intention, Australian Journal of Basic and Applied Sciences, vol. 5, no. 5, pp. 70-77, 2011.

[14] K. De Valck, G.H. Van Bruggen and B. Wierenga, Virtual communities: A marketing perspective, Decision Support Systems, vol. 47, no. 3, pp. 185-203, 2009.

[15] G. Dietz, and D.N. Den Hartog, Measuring trust inside organizations, Personnel Review, vol. 35, no. 5, pp. 557$588,2006$.

[16] D. Dong and H.M. Kaiser, Coupon redemption and its effect on household cheese purchases, American Journal of Agricultural Economics, vol. 87, no. 3, pp. 689-702, 2005.

[17] N. Donthu and A. Garcia, The internet shopper, Journal of Advertising Research, vol. 39, no. 3, pp. 52-58, 1999.

[18] G. Doumit, F.C. Wrigh, I.D. Graham, A. Smith, and J. Grimshaw, Opinion leaders and changes over time: A survey, Implementation Science, vol. 6, no. 117, pp. 1-6, 2011.

[19] M. Duggen and J. Brenner. (2013, February) The demographics of social media users - 2012. Pew Research Center. [Online]. Available: http://pewinternet.org/Reports/2013/Social-media-users.aspx

[20] T. Durukan, I. Bozaci and A.B.Hamsioglu, An investigation of customer behaviours in social media, European Journal of Economics, Finance and Administrative Sciences, vol. 44, pp. 148-158, 2012.

[21] R. Ellonen, K. Blomqvist, and K.Puumalainen, The role of trust in organisational innovativeness, European Journal of Innovation Management, vol. 11, no. 2, pp. 160-181, 2008.

[22] L.R. Flynn, R.E. Goldsmith and J.K. Eastman, Opinion leaders and opinion seekers: Two new measurement scales, Journal of the Academy of Marketing Science, vol. 24, no. 2, pp. 137-147, 1996.

[23] L.P. Forbes and E.M. Vespoli, Does social media influence consumer buying behavior? An investigation of recommendations and purchases, Journal of Business and Economics Research, vol. 11, no. 2, pp. 107-111, 2013. 
[24] J. J. Francis, M.P. Eccles, M. Johnston, A. Walker, J. Grimshaw, R. Foy et al. (2004, May) Constructing questionnaires based on the Theory of Planned Behavior. Rebeqi. [Online]. Available: http://openaccess.city.ac.uk/1735/1/TPB\%20Manual\%20FINAL\%20May2004.pdf

[25] D.E. Gibbons, Friendships and advice networks in the context of changing professional values, Administrative Science Quarterly, vol. 49, no. 2, pp. 238-262, 2004.

[26] R.E. Goldsmith and C.F.Hofacker, Measuring consumer innovativeness, Journal of the Academy of Marketing Science, vol. 19, no. 3, pp. 209-221, 1991.

[27] R. Gordon, Creating community-connection experiences, in Medill on Media Engagement (A. Peck and E. Malthouse, Eds.). Cresskill, NJ: Hampton Press, 2010, pp. 111-126.

[28] T. Hansen, Consumer values, the theory of planned behavior and online grocery shopping, International Journal of Consumer Studies, vol. 32, no. 2, pp.128-137, 2008.

[29] L. Harris and C. Dennis, Engaging customers on Facebook: Challenges for e-retailers, Journal of Consumer Behavior, vol. 10, no. 6, pp. 338-346, 2011

[30] J. Hartman and J. McCambridge, Optimizing millennials' communication styles, Business Communication Quarterly, vol. 74, no. 1, pp. 22-44, 2011.

[31] K. Heinonen, Consumer activity in social media: Managerial approaches to consumers' social media behavior, Journal of Consumer Behavior, vol. 10, no. 6, pp. 356-364, 2011.

[32] T. Hennig-Thurau, K. Gwinner, G. Walsh, and D. Gremler, Electronic word-of-mouth via consumer-opinion platforms: What motivates consumers to articulate themselves on the internet?, Journal of Interactive Marketing, vol. 18, no. 1, pp. 38-52, 2004.

[33] T. Hennig-Thurau, E.C. Malthouse, C. Friege, S. Gensler, L. Lobschat, A. Rangaswamy, and B. Skiera., The impact of new media on customer relationships, Journal of Service Research, vol. 13, no. 3, pp. 311-330, 2010.

[34] T. Hennig-Thurau and G. Walsh, Electronic word-of-mouth: Motives for and consequences of reading customer articulations on the internet, International Journal of Electronic Commerce, vol. 8, no. 2, pp. 51-74, 2003.

[35] S.C. Herring, I. Kouper, J.C. Paolillo, M. Tyworth, E.Wright, and Y. Ning, Conversations in the blogosphere: An analysis from the bottom up, in Proceedings of the 38th Annual Conference on System Sciences, HICSS, Hawaii, 2005, pp.1-11.

[36] C.K. Hsee and E.U. Weber, Cross-national differences in risk preference and lay predictions, Journal of Behavioral Decision Making, vol. 12, no. 2, pp. 165-179, 1999.

[37] J.Y. Hsieh and P.W. Liao, Antecedents and moderators of online shopping behavior in undergraduate students, Social Behavior and Personality, vol. 39, no. 9, pp. 1271-1280, 2011.

[38] L. Hsu, and C. Wang, A Study for e-trust in online auctions, Journal of Electronic Commerce Research, vol. 9, no. 4, pp. 310-321, 2008

[39] J.L. Joines, C.W. Scherer and D.A. Scheufele, Exploring motivation for consumer web use and their implication for e-commerce, Journal of Consumer Marketing, vol. 20, no. 2, pp. 90-108, 2003.

[40] A.M. Kaplan and M. Haenlein, Users of the world, unite! The challenges and opportunities of social media, Business Horizons, vol. 53, no. 1, pp. 59-68, 2010.

[41] E. Katz and P.F. Lazarsfeld, Personal influence: The Part Played by People in the Flow of Mass Communications, Glencoe, IL: Free Press, 1955.

[42] E.Y. Kim and Y.K. Kim, Predicting online purchase intention for clothing products, European Journal of Marketing, vol. 38, no. 7, pp. 883-897, 2004.

[43] K.J. Klein, B. Lim, J.L. Saltz, and D.M. Mayer, How do they get there? An examination of the antecedents of centrality in team networks, Academy of Management Journal, vol. 47, no. 6, pp. 952-963, 2004.

[44] P.K. Korgaonkar and L.D. Wolin, A multivariate analysis of web usage, Journal of Advertising Research, vol. 39 , no. 2, pp. 53-68, 1999.

[45] D. Koschutzki, K.A. Lehmann, L. Peeters, S. Richter, D. Tenfelde-Podehl, and O. Zlotowski, Centrality indices, in Network Analysis: Methodological Foundations (U. Brandes and T. Erlebach, Eds.). LNCS 3418, SpringerVerlag, 2005, pp. 16-61.

[46] C. Koyuncu and D. Lien, E-commerce and consumer's purchasing behaviour, Applied Economics, vol. 35, no. 6 , pp. 721-726, 2003.

[47] R.V. Kozinets, K. De Valck, A.C.Wojnicki, and S.J.S. Wilner, Networked narratives: Understanding word-ofmouth marketing in online communities, Journal of Marketing, vol. 74, no. 2, pp. 71-89, 2010.

[48] H. Kwak, R.J. Fox, and G.M. Zinkhan, What products can be successfully promoted and sold via the internet?, Journal of Advertising Research, vol. 42, no. 1, pp. 23-38, 2002.

[49] D.Z. Levin and R. Cross, The strength of weak ties you can trust: The mediating role of trust in effective knowledge transfer, Management Science, vol. 50, no. 11, pp. 1477-1490, 2004.

[50] B. Libai, R. Bolton, M. Bugel, K. de Ruyter, O. Gotz., H. Risselada, and A. Stephen, Customer to customer interactions: Broadening the scope of word of mouth research, Journal of Service Research, vol. 13, no. 3, pp. 267-282, 2010.

[51] N.J. Lightner, M.M.Yenisey, A.A. Ozok, and G. Salvendy, Shopping behavior and preferences in e-commerce of Turkish and American university students: Implications from cross-cultural design, Behaviour and Information Technology, vol. 21, no. 6, pp. 373-385, 2002.

[52] R.C. Mayer, J.H. Davis and D.F. Schoorman, An integrative model of organizational trust, Academy of Management Review, vol. 20, no. 3, pp. 709-734, 1995.

[53] H.D. McKnight, V. Choudhury and C. Kacmar, Developing and validating trust measures for e-Commerce: An integrative typology, Information Systems Research, vol. 13, no. 3, pp. 334-359, 2002. 
[54] M. Mohammadian and M. Mohammadreza, Identify the success factors of social media (Marketing Perspective), International Business and Management, vol. 4, no. 2, pp. 58-66, 2012.

[55] R.B. Money, M.C. Gilly and J.L. Graham, Explorations of national culture and word-of-mouth referral behavior in the purchase of industrial services in the United States and Japan, Journal of Marketing, vol. 62, pp. 76-87, 1998.

[56] J. Nahapiet and S. Ghoshal, Social capital, intellectual capital, and the organizational advantage, Academy of Management Review, vol. 23, no. 2, pp. 242-266, 1998.

[57] M.B. Naseri and G. Elliott, Role of demographics, social connectedness and prior internet experience in adoption of online shopping: Applications for direct marketing, Journal of Targeting, Measurement and Analysis for Marketing, vol. 19, no. 2, pp. 69-84, 2011.

[58] Nielsen. (2012, April) State of the media: The social media report 2012. Nielsen. [Online]. Available: http://www.nielsen.com/us/en/reports/2012/state-of-the-media-the-social-media-report-2012.html.

[59] B. Nooteboom, Social capital, institutions, and trust, Review of Social Economy, vol. LXV, no. 1, pp. 29-53, 2007.

[60] J. Owyang (2008, July) The 8 success criteria for Facebook page marketing, 2008. Altimeter. [Online]. Available: http://www.altimetergroup.com/research/reports/he-8-success-criteria-for-facebook-page-marketing

[61] C. Park and T.M. Lee, Antecedents of online reviews' usage and purchase influence: An empirical comparison of U.S. and Korean consumers, Journal of Interactive Marketing, vol. 23, no. 4, pp. 332-340, 2009.

[62] J. Perez-Carballo and C. Blaszczynski, Social media usage by business college students, Proceedings of the Academy of Information and Management Science, vol. 15, no. 2, pp. 5-8, 2011.

[63] D.K. Peterson, The Colbert bump $\AA$ and The Facebook ${ }^{\circledR}$ follow-through for generation snark: $A$ test and extension of The Ajzen's theory of planned behavior for 2012, Journal of Management Research, vol. 4, no. 3, pp. $43-65,2012$

[64] J. Pulakos, Young adult relationships: siblings and friends, Journal of Psychology, vol. 123, no. 3, pp. 237-244, 2001.

[65] V. Raghupathi, O. Arazy, N. Kumar, and B. Shapira, Opinion leadership: Non-work related advice in a work setting, Journal of Electronic Commerce Research, vol. 10, no. 4, pp. 220-234, 2009

[66] K. Ristig, The impact of perceived organizational support and trustworthiness on trust, Management Research News, vol. 32, no. 7, pp. 659-669, 2009

[67] E.M. Rogers, Diffusion of Innovations. NY: The Free Press, 1983.

[68] C.O. Ross, M. Sisic, J. Arseneault, M.G. Simmering, and R.R. Orr, Personality and motivations associated with Facebook use, Computers in Human Behavior, vol. 25, no. 2, pp. 578-586, 2009.

[69] I. Safko and D. Brake, The Social Media Bible. Hoboken, NY: John Wiley \& Sons Inc., 2009.

[70] A. Samson, Product usage and firm-generated word of mouth: Some results from Fmcg product trials, International Journal of Market Research, vol. 52, no. 2 pp. 459-481, 2010.

[71] L. Samutachak and D. Li, The effects of centrality and prominence of nodes in the online social network on word of mouth behaviors, Journal of Academy of Business and Economics, vol. 12, no. 2, pp. 125-148, 2012.

[72] J. Santrock, Adolescence: An Introduction. Dubuque, IA: Brown, 1987.

[73] L.G. Schiffman and L.L. Kanuk, Consumer Behavior. Upper Saddle River, NJ: Pearson Education, 2004.

[74] F.D. Schoorman, R.C. Mayer and J.H. Davis, An integrative model of organizational trust: Past, present, and future, Academy of Management Review, vol. 32, no. 2, pp. 344-354, 2007.

[75] A. Senecal and J. Nantel, The Influence of online product recommendations on consumers' online choices, Journal of Retailing, vol. 80, no. 2, pp. 159-169, 2004.

[76] D. Smith, S. Menon and K. Sivakumar, Online, peer and editorial recommendations, trust and choice in virtual markets, Journal of Interactive Marketing, vol. 19, no. 3, pp. 15-37, 2005.

[77] T. Sun, S. Youn, G. Wu, and M. Kuntaraporn, Online word-of-mouth (or mouse): An exploration of its antecedents and consequences, Journal of Computer-Mediated Communication, vol. 11, no. 4, pp. 1104-1127, 2006.

[78] M.S. Wang, C.C. Chen, S.C. Chang, and Y.H. Yang, Effects of online shopping attitudes, subjective norms and control beliefs on online shopping intentions: A test of the theory of planned behavior, International Journal of Management, vol. 24, no. 2, pp. 296-302, 2007.

[79] M.M. Wasko and S. Faraj, Why should I share? Examining social capital and knowledge contribution in electronic networks of practice, MIS Quarterly, vol. 29, no. 1, pp. 35-57, 2005

[80] A. West, J. Lewis and P. Currie, Students' Facebook friends: Public and private spheres, Journal of Youth Studies, vol. 12, no. 6, pp. 615-627, 2009. 